\title{
Telling a New Learning Story
}

\author{
Suzanne E. Martin \\ National College of Art and Design (NCAD), Creative Futures Academy \\ martins@staff.ncad.ie
}

\begin{abstract}
:
This paper sets out the possibility of changing the Design Learning conversation to one that reaches across design to the creative industries as a whole, and beyond. It suggests using Participatory Design techniques to shape transdisciplinary, creative knowledge and the growth of Communities of Interest (Col) through the establishment of a Designed Learning Framework, being piloted within the Creative Futures Academy (CFA) - a newly funded government initiative in Ireland. The author is part of the small team at the National College of Art and Design (NCAD), lead partner in a coalition of 3 Higher Education Institutions, building this CFA model. The knowledge generated within her recent research - investigating the design learning conversation within Higher Education being re-framed as a change-creation story to bridge the needs of institutions, private sector studios and multinationals - is helping inform and drive this first year of CFA development toward bold and curious approaches to curriculum design.
\end{abstract}

Keywords: learning design, participatory design, learning frameworks, preferable futures

\section{Can We Change the Conversation?}

In his research into the story of creative schools, artist and curator Vidokle (2006) noted that "education is not in stasis ... it is constantly being rethought, restructured and reinvented". At the UKADIA conference in 2014, Lucy Kimbell presented 'Some Futures for Art and Design Higher Education' (Kimbell, 2014), setting out an argument for the establishment of a new kind of institution in response to what she then cited as the key influences of change technology, practice, expanded field of design, the new informal education providers, and the expanded role of design in our world today. Like any good disaster movie, Kimbell told a story of current models crumbling, sinking or fading away, in a loosely pin-pointed future, the year 2020. Covid-19 is perhaps the greatest provocation for a paradigm shift, and the trigger for a release of creative energy that reimagines the Design School and design learning. Applying the lens of complexity theory (Davis \& Sumara, 2006) to the Design School current state in 2021, it is clear that formal design education simply cannot hold on to its inherently traditional position. From the ruins, an adaptive, more relevant model might grow. 
In 2020, three Irish higher education institutions led a successful bid to develop a new model for creative learning, with partners from the creative sector and industry, under the banner of the Creative Futures Academy (CFA). Awarded $€ 10$ million in Government funding, the CFA intends to invigorate the delivery of creative education for learners at all stages of their lives, and careers. This Academy aims to empower creative practitioners with sustainable and adaptable knowledge that build the critical attributes required to shape Ireland's future creative sector. As lead partner, the National College of Art and Design (NCAD) is fostering change-led thinking and a design-driven architecture for knowledge creation. It is a vision that will encourage the CFA, as a learning platform, to reimagine current-state systems, limitations, and participants.

\subsection{Understanding Change}

The rate of change during the 21 st century has prompted the design sector to think and talk differently. Consultancies and agencies have pushed 'user-centred' Design Thinking into the world beyond, and then into a mode of framing innovation (Dorst, 2015 and Mootee, 2013). This trajectory progressed to human-centred design (IDEO, 2009), and more recently, life-centered designing and thinking (Owens, 2019). It could be surmised that the response to change, from the sector, has primarily been terminology, that then, sometimes, changed behaviour. These shifts have partly been led by organisations such as IDEO, who [along with other dominant technology and innovation companies] extolled the virtues of circular thinking that moved us toward cradle-tocradle models of production and consumption (McDonough \& Braungart, 2002), before settling into systems thinking. They prompted the sector to understand design as an ecosystem around each action, product and activity (Escobar, 2018), thereby creating a new attitude toward how we define design (Rawsthorne, 2018).

In any private sector setting where design now lives, the teams working on solving problems are diverse, the level of complexity is too great for any one discipline to address (Mau, 2020). There is a need to find ways to support disparate Communities of Practice (CoP) becoming aligned Communities of Interest (Col). These Col could be defined as "groups similar to CoPs, but from different backgrounds, coming together to solve a particular [design] problem of common concern" (Arias \& Fischer 2000).

\section{A Testing Ground}

Paula Antonelli (2019) states that it is up to designers to teach the world how to use them well. Taking a changeled perspective on design learning, could encourage future designers "to exercise the acute critical sense that comes from their analytical training in order to help other citizens slow down, stop, reassess, and continue or change course." (Antonelli, 2019). The sector, and discipline, has a propensity toward disaggregation, to operate as silos defined by their distinction, which, ultimately, makes it harder for the world, for citizens, to use design for change. Tackling this at a Higher Education level, could take advantage of, what is, an uncertain scenario, one that has created an ideal testing ground for new [learning] ideas (Boym, 2010).

If private sector design has shifted from design as object-creation, to design as service for innovation, culminating in design as a service for thinking, then the educational component of it, has too been part of the Anthropocene, co-opted by the 'Capitalocene' (Davis \& Turpin, 2015). Design education and the Design School - as the defining provider of formal, accredited design education - has followed the money (Rodgers \& Bremner, 2019). It has introduced industry-relevant programmes, training designers to work in Service Design, Interaction Design, Design Research and so on. It equips students with the formulas that industry want. As theorist Frank 'Bifo' Berardi suggests in his essay 'Autonomy and General Intellect' (Berardi, 2013) the crisis of the university was embedded in the inability of modern humanism to cope with acceleration and complexity, "The university of the past, as we have inherited it from modernity, is unable to deal with networked intelligence". Another point that Berardi notes, one which echoes Roger \& Bremner's position, is that the process of privatisation has destroyed the university's autonomy, and thereby it's potential to produce knowledge. 
Whilst we have seen the reinvention of some traditional institutions such as the Willem de Kooning Academy (Chabot, 2013) and the Sandberg Institute (de Vet, 2020), schools which err on the radical side of learning, that are independent of the restrictions of universities with long-established reputations, often reside at the edge of academia without responsibility to reshape the system. If design is to be a "cognitive, pragmatic and political tool" (Antonelli, 2019) and take a restorative role in change, then the change needs to start with the evolution of the Design School. Shaping learning that supplies the needs of a current system does not encourage change. Shaping learners that cannot challenge the contexts around them, does not allow for change.

\section{Energy and Transformation}

Art director and curator Koyo Kough describes change, both local and global, as being the aspiration of social design, and questions that if social design is a site for 'things' that create a better life, then political activity must not be excluded from that equation. They argue that, "popular uprisings help shake the tree... A legitimate aspiration for a better life and good governance depends on access to or creation of tools that allow the achievement thereof." (Kough, 2019)

Design Learning must be considered one such tool. Editors and authors, Ivison and Vandeputte (2013. p. 27) discuss how recent design education experiments may have come about for simple practical, academic or social reasons. They state that the context of "the higher education crisis has given them new and broader political relevance. Self-organised schools and alternative learning platforms can be understood both as critical responses to the academic establishment and as speculative attempts to develop viable alternative spaces and models of learning". However, artist, writer and activist Gregory Sholette (2013) warns against embracing a plenary community model of learning. He slates pedagogical activism as simply being the latest novel form of cultural resistance to the neoliberal enterprise culture and its 'society of risk' ethos.

In light of the changing nature of design, Sachetti (Boelen et al 2020) states that learning should be "a permanent, embodied attitude, one that transcends the formal, spatial and temporal boundaries of the school, and overflows into the world and life itself." Institutions of learning, especially art and design schools have always been inextricably linked to the new wave, to social, political and educational uprising and change, intervening to support a ripple of change that radiates out to a wider community. John Thackara outlines philosopher Joanna Macy's proposition for an emerging story, the 'Great Turning', as a being profound shift in perception and the realisation that we are part of a complex of living systems. He describes it as a quietly unfolding transformation (Thackara, 2015).

The student revolts of 1968 were a transformative moment when divergent groups held a shared social and intellectual purpose and triggered an energy release in the system (Tickner, 2008 and Colomina, 2015). 2020's pandemic and the resulting enforced shift to distance learning was a trigger for the Design School to move beyond disruption and enter a state where transformation and organisational change were adopted. Design learning finally embraced an allocentric outlook where it responded to, and acted with, learner isolation to establish fluid ways of making and being in the world (Renfro, 2009).

With the power of networked intelligence, comes capacity to control the model through collaboration and cocreated meritocracy. In 'Decolonising Knowledge' (Petti, 2015), Alessandro Petti describes Al-Quds Bard 'Campus in Camps' model which responded to the social implications of the first intifada in Palestine (1987) where schools and universities were closed, leaving a population without any formal structures (physical and theoretical) for learning. Out of sheer necessity, education became an organic, underground network. Petti depicts a scene of emancipation that theorist Berardi (2013) stated should be the ambition of education; universities, unconfined by walls and campuses, set up by teachers and students that met learners where they were.

Al-Quds Bard 'Campus in Camps' moved with the changing needs of learners. Embodying the tenets of a participatory project (Foth and Axup, 2006), every stage of Al-Quds Bard 'campus in camps' allowed the learning community to define its goals, contribute to teaching and learning in their own terms and to take ownership of the 
decision-making process. Conflict and crisis became factors of change and empowerment. If education is about developing pedagogies to link ideas, practices and values under conditions of uncertainty (Shulman, 2005) then what happened to formal education in Palestine after 1987 is relevant to tomorrow's learning narrative.

D\&AD's New Blood Shift programme, address tomorrow's sectoral needs, today, by focusing on greater accessibility and diversification (Gadgil, 2016) across design. Students participate in a series of entrance exercises where-upon they are selected to work on group briefs with industry, in the evenings, so they can learn whilst sustaining an income. Culminating in paid placements in industry, the programme foregrounds experience as learning (Jackson, 2011) and work-based learning (Boud and Solomon, 2001).

Author and educator, John Danvers (2003) distilled the need for educational change, arguing that we need "a reorientation of learning... around a process-based pedagogy that places particular emphasis on indeterminacy, pluralism, revisibility and dialogue". Renowned architect and educator at the Architecture Association (London), Elia Zengelis (2015) suggests that learning institutions adopt a community model, one with shared power for staff and students. He proposed that institutions adopt a collective leadership (Denis et al, 2010) model, something that is, now, increasingly pertinent to participatory approaches to remote or blended Design Learning.

\section{Shaping the Conversation}

Petti's work in Palestine demonstrates how space can inform communal learning (Renfro in ed. Madoff, 2009) and how knowledge, might emerge from group effort, not the structure of an institution. It attempted to move from the production of knowledge - based on information and skills - to processes of learning based on perceptual shifts, critical approaches and governing principles.

The Creative Futures Academy (CFA) presents an opportunity for NCAD, as lead partner, to develop and introduce a Designed Learning Framework (DLF) that underpins a creative, undisciplined, team-based learning model, open to a wider demographic of learner than the partner currently attract (HEA, 2021. In turn, this DLF might be introduced as a strategic learning infrastructure for the enhancement of existing Undergraduate and Postgraduate programmes across the college.

Currently in Phase 1 of the 12 month R\&D process (of a four year development project), NCAD's model for the CFA is emerging as an interconnected set of frameworks that support pedagogical investigation toward becoming the DLF. Piloting two new course structures, with a suite of assets to support staff developing their projects, September 2021 sees the first iteration of the emerging model. Focused on applying communication-led, thematically driven, thinking, framed by Participatory Design techniques, these pilots build toward a fluid infrastructure that stages a spectrum of transdisciplinary learning.

The development of a conceptual, learning development package - which includes dialogue structures, dialogue tools, design templates and theoretical referencing - encourages existing, and new, Learning \& Teaching practices to move to a Problem-Based Learning (PBL) position of designing, and support it when it arrives (Powers, 2017). Shaping the CFA requires explicit application of design methodologies and thinking, as an engine for creating criticality, and facilitating a shift in learning approaches.

\subsection{Learning Participation}

Dialogue is a powerful cognitive tool, in learning, and in life. it is a bridge between states. There is opportunity to expand engagement and focus on how learning conversations are formed, dialogues are shaped and knowledge is scaffolded. The Sandberg Institute frames design as 'a tool to deal with reality, to relate to complex truths, as a compass to find your way and figure out what matters'. (de Vet 2020). Any 'new' model should develop 
knowledge through discursive design learning activities, the creation of dialogues with tangible support tools, and learning that is 'in the wild', beyond the school.

Participatory Design (PD) finds ways to involve different (not necessarily design) stakeholders around a design project and/or product during its development, with the design, using various co-designing activities throughout the design process (Schuler \& Damioka, 1993). These methods and practices, have become widely and variably adopted across social sciences, design, media, technology (Huybrechts, 2014) and can be seen to influence both Agile working and inform Design Thinking practices within multinational studios (Muratovski, 2015). However, as with many paradigms, corporate adoption has lessened the resonance, and diluted the experience of Participatory Design (Smith and Iversen, 2018).

The ecology of learning and relational values of learning through placing it in the context of a lived life is critical to creating embedded, embodied, knowledge. It is critical to the positive impact of PD in learning, and working. David Garwin outlines that "Learning is the key to success - some would even say survival - in today's organisations. Knowledge should be continuously enriched through both internal and external learning. For this to happen, it is necessary to support and energise [the] organisation, people, knowledge, and technology for learning" (Garwin, 2013). He goes on to stress the importance of communication systems in helping forge a learning culture, to "facilitate the lateral transfer of information and knowledge across formal structural boundaries."

Leading Human Resource academics Marsick and Watkins (2003) defined six key characteristics that any organisation should address, to ensure a productive operational learning culture. These could, and should, be equally critical to an institution that delivers learning, they are:

1. Create continuous learning opportunities.

2. Promote inquiry and dialogue.

3. Encourage collaboration and team learning.

4. Create systems to capture and share learning.

5. Connect the organisation to its environment

6. Provide strategic leadership for learning.

\subsection{Situated Design Learning}

Participatory Design cannot be defined as a singular method, there is no participatory design process as such (Sanoff, 1990). By necessity, participatory design practices are situated, and each project is contextually relevant, meaning that each application is embedded and is designed to suit specific characteristics and circumstances (Simonsen, Sabo et al., 2014).

Given its 'situated' nature, a core concern for designers advocating the use of Participatory Design is how to scale-up from or build upon what has been learnt in one situation to other organisational settings. Karasti (2014) discusses whether there could be "reforms of infrastructuring that fit with the situated but aren't capable of crossing boundaries... [of] scales and scope".

Jean Lave and Etienne Wenger (1991) coined the term 'situated learning', arguing that "learning is situated in the sense that it takes place through legitimate peripheral participation in a community of practice." (Simonsen et al, 2014). Simonsen suggests that fostering this process to embed design learning within design teams, studios and organisations is not something that can be delivered solely by a top-down approach such as a curriculum, but rather requires a collaborative process where learners actively participate and participants actively learn through interaction. 


\subsection{Dialogic and Discursive Design}

The notion of tools that help facilitate dialogues has been developed by design academics, Louise Ravnløkke and Anne Louise Bang. They moved from proposing 'tools for dialogue' (Bang, 2010) to coining the term 'Tangible Dialogue Tools' (Ravnløkke \& Bang, 2016),

As an emerging form of participatory design, innovation researcher Peter Jones, describes it as the "practice of structuring collective language and non-verbal discourse to enact design processes" (Sanders and Stappers, 2012, p. 252). He argues that the role of dialogue in design research is underdeveloped and that a range of appropriate dialogic methods could usefully be employed in design fieldwork and knowledge translation.

Tharp \& Tharp (2013) define this category of creative practice as "the creation of utilitarian objects/services/interactions whose primary purpose is to communicate ideas." They identify that a level of deliberate ambiguity and open-mindedness is often leveraged with these discursive instruments, and Gaver (2003) states that ambiguity allows designers to "suggest issues and perspectives for consideration without imposing solutions... to raise topics or ask questions while renouncing the possibility of dictating answers." This approach builds upon the Critical Design language of Dunne and Raby (Dunne 1999 and Dunne \& Raby 2001), and promotes the thinking that design can communicate substantive ideas that are relevant to individuals, collectives and society as a whole.

\subsection{Institutioning and Infrastructuring}

In attempting to institutionalise participatory ways-of-working and ways-of-learning within private sector organisations and Design Schools, there is a need to develop new frameworks and processes that can foster the necessary, sustained, and continuous, dialogue and discourse between disparate communities of practice (CoP), over periods of time. These practices can be moved toward becoming Communities of Interest (Col) where common, underlying thematic themes support innovative design thinking, doing and learning.

'Institutioning', is an evolving practice addressing the need for strengthened communication between diverse actors within any institution. It has proved effective in improving participatory design by attempting to shift the institutional framing of actors. Institutioning can be described as the "gradual process of altering (consolidating or challenging) existing frames of institutions" (Huybrechts et al. 2017).

The process of infrastructuring, is "characterised by a continuous process of building relations with diverse actors" (Hillgren et al. 2011). Successful infrastructuring can improve communication and build a resilient learning culture by sustaining, embedding and empowering Participatory Design beyond its use within client and/or research activities i.e. moving it toward a culture, a way-of-being.

\section{Designing a new Learning Story}

The Irish Government commissioned a report, 'Together for Design' (DBEI, 2019), to understand the impact of design on the Irish economy, and the inter-connected needs that must be addressed for design to reach its potential. One sectoral recommendation was that the connection between Higher Education and enterprise required focus.

As an alliance of three Higher Education Institutions - the National College of Art and Design (NCAD), University College Dublin (UCD) and Dún Laoghaire Institute of Art, Design and Technology (IADT) - the CFA is co-creating and co-delivering an evolving curriculum with industry and cultural partners (such as the Institute of Designers in Ireland and the Design and Craft Council of Ireland) that ensures its vision is designed 'with', rather than 'for' . By 
moving beyond merely upskilling learners to uncritically design probable futures, based on existing paradigms, the academy hopes to empower graduates to propose, create and evaluate preferable futures that actively change society and industry.

As the CFA project develops across the four years, NCAD's emerging Designed Learning Framework, informed by robust dialogue and discourse with the sector, is being co-designed with partner organisations to help embed a new learning culture and infrastructure within corporate, creative and public sector institutions. With the CFA, NCAD seeks to promote a restorative learning approach that transcends the existing Irish model of creative education. It is an opportunity to develop a best-practice model of inter-institutional collaboration and governance that could be scaled up and/or replicated across the regions (and beyond Ireland), according to dynamics, demands and opportunities.

The project will communicate its learnings, iterations and methods throughout its initial four year duration, and hopes to actively collaborate with international colleagues to develop, what might be, a preferable story of designed, and design-led, creative learning.

\section{References}

Antonelli, P. (2019). Broken Nature: Design Takes on Human Survival (Triennale De Milano). Rizzoli Electa.

Arias, E., Eden, H., Fischer, G., Gorman, A., and Scharff, E. (2000). Transcending The Individual Human Mind Creating Shared Understanding Through Collaborative Design. ACM Transactions on Computer-Human Interaction (TOCHI), 7(1), 84-113.

Bang, A. L. (2010). Emotional Value of Applied Textiles. PhD Thesis, Design School Kolding.

Berardi, F. (2013). Autonomy and General Intellect. Contestations: Learning from Critical Experiments in Education. Bedford Press.

Boelen, J. (2018). Design as Learning: A School of Schools Reader. Valiz

Boud, D. and Solomon, N. (2001). Work-based Learning: a New Higher Education?. McGraw-Hill Education (UK).

Boym, C, (2010) Teaching in a Time of Uncertainty, Design Observer. Available: from http://designobserver.com/feature/teaching-in-a-time-of-uncertainty/14378/ (Accessed on 6 September 2020]

Chabot, J. (2013). Reflections on Art Education. Re-Inventing the Art School 21st Century. WDKA.

Colomina, B., Kotsioris, E., Galan, I. and Meister, A. (2015). The Radical Pedagogies Project. Learning Network, 45.

Danvers, J. (2003). Towards a Radical Pedagogy: Provisional Notes on Learning And Teaching in Art \& Design. International Journal of Art \& Design Education, 22(1), pp.47-57.

Davies, H. and Turpin, E. (2015). Art \& Death: Life Between The Fifth Assessment and Sixth Extinction in Art. The Anthropocene: Encounters Among Aesthetics, ed. Davies, $\mathrm{H}$ and Turpin, E. Open Universities Press.

Davis, B., \& Sumara, D. J. (2006). Complexity And Education: Inquiries Into Learning, Teaching, And Research. Psychology Press.

DBEI, (2020). Together for Design: Digital, Product and Strategic Design Skills of the Future. DBEI

Denis, J. L., Langley, A., \& Rouleau, L. (2010). The Practice of Leadership in The Messy World of Organizations. Leadership, 6(1), 67-88.

de Vet, A. ed. (2020). Design Dedication - Adaptive Mentalities in Design Education. Valiz.

Dorst, K. (2015). Frame Innovation: Create New Thinking by Design. MIT press.

Escobar, A. (2018). Designs For The Pluriverse: Radical Interdependence, Autonomy, And The Making of Worlds. Duke University Press.

Foth, M. and Axup, J. (2006). Participatory Design And Action Research: Identical Twins or Synergetic Pair?. In Expanding Boundaries in Design: Proceedings Ninth Participatory Design Conference 2006 (Vol 2) 9396. Computer Professionals for Social Responsibility.

Gadgil, S. (2016), Back To School, Creative Review (September 2016), 32 - 36.

Garwin, D.A. (1993). Building a Learning Organization. Harvard Business Review, 71(4), 73-91.

Gaver, W.W., Beaver, J. and Benford, S. (2003). Ambiguity as a Resource For Design. Proceedings of The SIGCHI Conference on Human Factors in Computing Systems, 233-240.

HEA - Access Statistics Summary. Available: from https://hea.ie/policy/access-policy/access-

statistics-summary/ (accessed on 23 August 2021)

Hillgren, P.A., Seravalli, A. and Emilson, A. (2011). Prototyping and Infrastructuring in Design For Social Innovation. CoDesign, 7(3-4), pp.169-183.

Huybrechts, L., Storni, C., Lee, Y., Schepers, S., Schoffelen, J. and Dreessen, K. (2014). Participation is Risky. Approaches to Joint Creative Processes (Vol. 13). Valiz.

Huybrechts, L., Benesch, H., \& Geib, J. (2017). Institutioning: Participatory design, Co-design And The Public Realm. CoDesign, 13(3), 148-159. 
IDEO (2009). The Human-Centred Design Toolkit. IDEO

Ivison, T. and Vandeputte, T. (2013). Contestations: Learning from Critical Experiments in Education. Bedford Press.

Jackson, N. J. (2011). Learning For a Complex World: A Lifewide Concept of Learning, Education and Personal Development. Authorhouse.

Karasti, H. (2014). Infrastructuring in Participatory Design. Proceedings of the 13th Participatory Design Conference: Research Papers-Volume 1 (pp. 141-150).

Kimbell, L. (2014). 'Some Futures For Art and Design Institutions'. UKADIA Conference. Available: from https://ukadia.ac.uk/wp-content/uploads/2014/03/Lucy-Kimbell-transcript-260214.pdf (Accessed on 20 May 2021]

Koyo Kouoh, K. (2020). Never Despair, Your Miracle is Around the Corner: The Multiple Forms of Designing the Social. Broken Nature: Design Takes on Human Survival (Triennale De Milano). Rizzoli Electa.

Lave, J., \& Wenger, E. (1991). Situated learning: Legitimate Peripheral Participation. Cambridge University Press.

Marsick, V.J. and Watkins, K.E. (2003). Demonstrating The Value of an Organization's Learning Culture: the Dimensions of The Learning Organization Questionnaire. Advances in Developing Human Resources, 5(2), pp.132-151.

Mau, B. (2020). Bruce Mau: MC24: Bruce Mau’s 24 Principles for Designing Massive Change in your Life and Work. Phaidon.

McDonough, W. and Braungart, M. (2002). Remaking The Way we Make Things: Cradle to cradle. North Point Press, p.104.

Møller, T., Petersen, L. R. M., \& Bang, A. L. (2016). Tangible Dialogue Tools: Mediating Between Nonverbal Users and Everyday Experts.

Mootee, I. (2013). Design Thinking for Strategic Innovation: What They Can't Teach you at Business or Design School. John Wiley \& Sons.

Muratovski, G. (2020). Don Norman: The Future of Design Education, Available from: https://www.youtube.com/watch?v=b U6gyTZyoQ\&list=PLBc7sGyArxaZ3u6kxCN0qVvvDT9TcVnQM\&index=5 (Accessed 2 January 2021).

Owens, J. (2019) 10 Principles of Life Centered Design: How We May Begin to Design for a Future of Inclusivity. https://medium.com/the-sentient-files/10-principles-of-life-centered-design-3c5f543414f3 (Accessed 10 August 2020).

Petti, A . (2015). Decolonising Knowledge. Volume 45: Learning. Archis.

Powers, M. N. (2017). Self-regulated Design Learning - A Foundation and Framework for Teaching and Learning Design. Routledge

Rawsthorne, A. (2018). Design as an Attitude. JRP.

Renfro, C. (2009). Undesigning The New Art School. Art School Propositions for the 21st Century. MIT Press.

Rodgers, P. and Bremner, C. eds. (2019). Design School: After Boundaries and Disciplines. Vernon Press.

Sanders, E.B.N. and Stappers, P.J. (2012). Convivial Toolbox - Generative Research for the Front End of Design. BIS.

Sanoff, H. (1990). Participatory Design: Theory \& Techniques. Henry Sanoff.

Sholette, G. (2013). Counting on Your Collective Silence: Notes on Activist Art as Collaborative Practice.

Schuler, D. and Namioka, A. eds. (1993). Participatory Design: Principles and Practices. CRC Press.

Shulman, L.S. (2005). Signature Pedagogies in the Professions. Daedalus, 134(3), 52-59.

Simonsen, J. and Robertson, T. eds. (2012). Routledge International Handbook of Participatory Design. Routledge.

Simonsen, J. ed. (2014). Situated design methods. MIT Press.

Smith, R. C., \& Iversen, O. S. (2018). Participatory Design for Sustainable Social Change. Design Studies, 59, 9 36.

Thackara, J. (2015). How to Thrive in The Next Economy. Thames \& Hudson.

Tickner, L. (2008). Hornsey 1968: The Art School Revolution. Frances Lincoln Itd.

Vidokle, A. (2006). Exhibition as a School in a Divided City, Notes for an Art School. Manifesta 6.

Zengelis, E. (2015). 'A Revolutionary Suggestion'. Volume 45: Learning. Archis.

Author Bios:

Suzanne E. Martin With two decades of experience across the sector and academia, the author recently concluded an investigation into learning cultures within multinationals and the design school. She undertook a 1 year role as Lecturer in Creative Pedagogy for the CFA at NCAD, in June 2021.

Acknowledgements: Thanks to Professor Alex Milton (FRSA, FIDI), Head of School of Design, and Professor Sarah Glennie, Director, at the National College of Art and Design (NCAD) for their support. 